\title{
The Effect of Applying International Accounting Standards on Accounting Values in Iraq (Experiences of Some Countries): A Review
}

\author{
*Khudair Majeed Allawi, **Hussein Hoshan Jarullah, \#Alaa Saleh Abdallah \\ *Al-Furat Al-Awsat Technical University-Technical Institute Diwaniya.Iraq \\ **General Directorate for Education of Thi-Qar.Iraq \\ \#General Directorate for Education of Thi-Qar -Iraq
}

DOI: $10.37648 / \mathrm{ijrssh} . v 10 \mathrm{i} 04.017$

Received:20 ${ }^{\text {th }}$ September, 2020; Accepted:20 ${ }^{\text {th }}$ October, 2020; Published:26th October, 2020

\begin{abstract}
This stady aims to review the effect of applying international accounting standards on accounting values in light of the changes and developments in the economic environment, which called many countries to adopt international accounting standards, which was reflected in the reality of accounting practices as well as on the accounting values of those countries. The research problem is through the questioning that The research raises what are the effects resulting from the application of international accounting standards on the accounting values of the countries that adopt those standards. The researcher assumed that the application of international standards has a clear effect on the accounting values and in varying proportions between countries, especially in the long term for the application of these standards.

Keyword: international accounting standards, accounting values.
\end{abstract}

\section{INTRODUCTION:}

In light of the utmost importance of accounting standards as guides for implementation, awareness of the variables and dimensions of a society's culture is one of the necessary matters when setting accounting standards for that society. That the process of developing and developing accounting standards is a continuous process through which accounting responds to the emerging problems and new transactions and to the changes that occur in any of the prevailing environmental and societal conditions, Dicks, 2010: 70). The achievement of consistency and harmony in preparing financial reports It is considered an urgent need in this era, especially in light of the major economic conglomerates and the emergence of multinational companies, which requires meaningful comparisons of the financial information that emanate from the different countries that use accounting standards, which were recently different (Ed, 2007: 65)). Many international accounting bodies have sought to try to standardize, harmonize and even standardize accounting practices, which culminated in the last issuance of international accounting standards and international financial reporting standards, which made the financial statements more clear and more understandable.

Accounting thought has witnessed, for many years, an increasing recognition and interest in the impact of international accounting standards on accounting systems and practices and their development in the different countries that started applying these standards and whose effect on accounting values was observed in those countries. (Al-Rawi, 2009: 27) The effect of these standards on 
accounting values results either as states seek to develop their accounting systems to keep pace with the pace of development or as a result of pressures imposed on them as a result of their application of these standards, or as an attempt to converge and explain the differences or similarities between accounting systems and practices in Two countries or in a number of countries, (Altrad, 2005: 63) or as a result of the impact of the accounting values adopted by the International Financial Reporting Standards, and in this research paper we try to demonstrate the impact of international accounting standards on the accounting values and stand on the most important reasons for the countries that apply these standards from The change in its accounting values, as well as the addition of accounting practices and applications.

\section{FIRST: LITERATURE REVIEW}

The economic expansion at the international level, the development in the level of world trade, and the spread of multinational companies increased the need to simplify and facilitate the rules and procedures and their approach among the countries of the world for the purpose of contributing to the acceleration of development and the movement of saved money and encouraging investors to move in a large scale. Broader by reaching joints or points of convergence between the international and national accounting standards (Al-Trad, 2005: 63), and the presence of appropriate accounting standards represents a good sign to protect the rights of the groups that use the financial statements that depend on them in managing their affairs. After World War II, the world knew each country's commitment to its own accounting system,( Dicks ,2010: 70) which is called US GAAP: (Generally Accepted Accounting Standards), a term used by US accounting bodies to express the peculiarity of the American accounting system. (Ismail, 2007: 86) In fact, the beginning of the interest of the United States of America, as the largest capitalist and economic pole, in accounting issues was after the economic depression that struck it and the whole world in 1929, when the US Congress at that time enacted two laws that created them. The Financial Market Authority (SEC) in 1933, was subsequently followed by another law issued in 1934 on the mechanism of securities exchange activity, and this was in order to regulate the American financial markets. (Coyle, 2015: 22) In addition to this and given what the accounting profession requires From the great experience of its professionals, the United
States of America paid special attention to forming a temporary committee, in the beginning, to create and develop accounting standards through the American Institute of Certified Public Accountants (Bob, 2001: 87))

(AICPA) called the Committee for Accounting Procedures (CAP), the latter was able, for the period between 1938 and 1959 , to develop 51 accounting standards at the local level. Then, at the end of 1959, this committee was replaced by an Accounting Principles Board that managed on its part to develop 31 new accounting standards, and that was 14 years after the inauguration of its members. After that, and in 1973, the Financial Accounting Standards Board was established) FASB: Financial Accounting Standards Board (, holding in this regard the responsibility for accounting development, but in the presence of permanent coordination with the torch holder, which is the American Institute of Certified Public Accountants (AICPA). (Galant. \& Brian, 2007: 67) After the restructuring of the International Accounting Standards Committee, the International Accounting Standards Board emerged with the aim of developing and disseminating international accounting standards and strengthening them as well as enhancing their use on a global scale. In 2002 the Council renamed the existing SIC Interpretations Committee and replaced it with the IFRIC Interpretations Committee. Interpretation and clarification of the existing accounting standards, in addition to providing guidance and directions on a permanent basis on the existing international accounting standards and on international financial reporting standards. It also helps ifric to achieve convergence of international standards by working on Similar groups are sponsored by national accounting standard setters. It seems that the late decades of the end of the last century and the beginning of the current century witnessed great and accelerating developments at the local and global level in various fields and caused wide changes in the intellectual framework or method of practicing the accounting profession as well as an increase in the orientation towards joint-stock companies and the revitalization of financial markets, Martines, 2007: 15). This, in turn, confirms the increased need for appropriate and comparable financial information to make various decisions that reflect the economic face of the event, and this requires the availability of accounting standards that limit accounting methods and procedures and are prepared according to a conceptual framework consistent with concepts and objectives. Frederick, 2008: 97)) The 
international accounting standards have become a reference to which accountants and professionals from most countries of the world, especially the developing countries, do not have local standards that govern professional practices. Accounting as the language of business. (Issa, 2004: 54) The increasing pressure from many users of information prepared with high-quality standards that are comparable regardless of the different exporting countries, including shareholders, investors, creditors, financial analysts, international organizations and governments, have led to the emergence of several scenarios. To set one set of accounting standards at an international level, represented by holding international conferences since the beginning of the twentieth century, and among the general objectives that are pursued through adopting or implementing IFRS are the following: (Shehata, 2008: 56)

-The trend towards globalization in the practice of business activity.

-Achieving the principle of transparency in announcing profits

-Improving forecast accuracy by improving the quality of accounting information

-Reducing costs (bypassing the issue of double-use accounting standards)

-Improving the level of internal control for the activity

-Improving the comparison areas for investments outside the country's local borders

-Reducing the size of the approved regulations and instructions. Currently, IFRS contains about 2,000 pages, while under US GAAP this includes 25,000 pages.

-Improving the quality of the accounting standard, and achieving the fair value principle.

\section{SECOND: ACCOUNTING VALUES AND THEIR DIMENSIONS:}

In a pioneering study Gray 1988 identified four dimensions of accounting values in any society:

1- Professional versus legal oversight: as professionalism reflects allowing scientific organizations and societies to play their role in setting procedures and regulations and issuing standards and rules that govern professional performance, while legal oversight expresses the authorities 'interference in defining the systems and rules that govern professional practices (Issa, 2004: 54) And that the accounting societies in which the professionalism prevails is more flexible in accounting practices, and then it is desirable that accounting standards be issued, including the principles of accounting measurement and estimation for economic operations (Bob, 2001: 87)) in a sense that fits those societies approach to the principles, while societies where legal control prevails will prefer Standards are issued ,Accounting in the form of specific rules for application in practice in the sense that it prefers the introduction of rules in building accounting standards. (Abdelkader, 2013: 6)

2- Consolidation versus flexibility: Consolidation refers to adherence to unified accounting systems and practices and adherence to them from one period to the next, while flexibility is based on preferring diversity in practices according to the different circumstances surrounding the company. (Bob, 2001: 87)), and then the appropriate approach in building standards is the entrance to the rules, while accounting societies in which flexibility prevails. Society prefers that accounting standards be issued, including principles of accounting measurement and estimation for economic operations, in a sense that fits those societies approach to principles. (R. Krugman, 2005: 62)

2- 3-Reserving versus optimism: Accounting conservatism indicates that measurement in light of uncertainty about future events and is reflected in turn on presentation and disclosure, while optimism reflects the ability to bear risks related to uncertainty. The accounting societies in which the accounting reservation prevails tends more to strict adherence to rules and laws Hence, the society prefers that accounting standards be issued in the form of specific rules for application in practice in the sense that it favors the introduction of rules in building accounting standards. Bob, 2001: 87)) While accounting societies where optimism prevails, individuals are willing to take risks and not be bound by conservative accounting practices, and then they would prefer to issue accounting standards, including principles of accounting 
measurement and estimation for economic operations, in a sense that fits those societies approach to principles. R. Krugman, 2005: 62(

4 -Confidentiality versus transparency: Confidentiality refers to the trend towards setting controls and restrictions on accounting information that is communicated to external parties, while transparency refers to expanding accounting disclosure to all categories of users of financial statements (Faris, 2011: 54) that the accounting societies that prevail in secrecy will prefer that Accounting standards are issued in the form of specific rules for application in practice for fear of the issue in the event of disclosure of any information that is too much in the sense of R. Krugman, 2005: 62)) Preferring the introduction of rules in building accounting standards while the accounting societies in which transparency prevails are Reflecting secrecy in the fields of politics, ethics, business, administration, law, economics, and sociology. It means full explanation and clarity, and then society prefers to issue accounting standards including principles of accounting measurement and assessment of economic operations, in a sense that suits those societies approach to principles.

\section{THIRD: THE DIFFERENCE IN ACCOUNTING VALUES}

Studies and research vary in terms of their identification of environmental variables and in terms of the number of variables that are focused on, and in general there is no general agreement on a comprehensive identification or inventory of these variables, so the difference in accounting practices and values is expected between countries because it results from a complex interaction of different Economic, historical, organizational and cultural factors. Among these factors we mention: Cheng, 2007: 32)

1- The nature of the legal system: Legal system

A distinction can be made between two types of legal systems that affect the nature of values and the prevailing accounting system, and they are: (Ghattas, 2007: 17(

A) The general law system: According to this system, the law includes a limited number of articles that contain general provisions for specific cases that the courts interpret with regard to the various cases brought before them. And the judgments issued by the courts in the cases represent an integral part of the texts of the law, F. Martines, 2007: 31)) and the accounting practices in this system are based mainly on professional judgment even as they are formulated in the form of accounting standards. This system originated in England, then the United States, and the British Commonwealth countries.

B) The Roman Law System: According to this system, the law includes detailed provisions that have been applied in different cases, and here we find that the corporate law, for example, includes accounting principles, valuation rules, income measurement principles, and the content and form of financial statements. And this system prevailed in many countries such as Japan and European countries except for Britain. Bob, 2001: 87(

2-Tax legislation: Tax legislation is considered one of the environmental variables that affect accounting values and practices in countries, and we distinguish between two cases (Isa, 2004: 54:(

A) The independence of both the foundations of accounting measurement and the foundations of tax measurement: we find here that the rules governing accounting measurement differ fundamentally from what we dictate by the provisions of laws and tax instructions, and this difference leads to the appearance of the deferred tax item in the financial statements, which may Sometimes its value reaches huge sums.

B) a strong influence of the rules of accounting measurement, which may sometimes reach a full correlation between them.

3- Types of ownership and main sources of financing: It is possible to distinguish between two types of ownership: Cheng, 2007: 32))

A) Most or all of the economic units are owned by the government: When the government is the main source of financing as the owner of all units, it becomes the sole and main user of accounting information, and this leads to the standardization of the accounting system and the standardization of measurement and disclosure practices.

B) Most or all of the economic units are owned by the private sector: In the case of the domination of the private sector over the economic activity, ownership may take the 
family pattern, the closed company pattern, a stretch in which the ownership is distributed among a large number of individual investors and the type of investment institutions. In addition, banks in some countries play a major role in contributing to the capital of economic units, which creates a distinct pattern for financial institutions' participation in ownership. R. Krugman, 2005: 62(

4-Political and economic influence: the accounting system arose and developed in many countries by simulating an accounting system in another country under the influence of political influence or economic influence of that country: (Mustafa, 2006: 34), and the most influential country in this field is Britain, France and the United States, where we find, for example, that the Algerian accounting system has broken away from the French accounting system.

5- Inflation: Inflation is one of the features of the economic environment in which accounting operates, and the level of inflation determines the extent of the need to disclose the impact of the change in price levels 6 , and then the measurement and accounting disclosure are based on the historical cost basis, and the disclosure of the impact of the change in levels Prices can in turn contribute to influencing the inflation rate (Al-Hinnawi, 2007: 15(

6-The level of economic development: This factor affects the type of economic operations and determines which type is appropriate, Martines, 2007: 18), as we find that the type of operations determines the type of accounting issues that can be faced, as many industrial economies have transformed into economics. Services, and thus became the new challenges of accounting is the assessment of human resources and intangible resources. Jagerson, 2006: 59(

7- Cultural factors and societal dimensions: Hofsted's study is the pioneering study on the dimensions of societal values and their effects. Four dimensions of societal values, which were considered to reflect the cultural orientation of any country, and they are: - (Al-Buhais:, 2006: 98)

A) Individualism versus social solidarity: Individualism represents the individual's concern for their personal interests and the interests of their families only (a coherent social framework). As for social solidarity, individuals from their families or individuals belonging to their group are expected to take care of their interests in exchange for unlimited loyalty (a coherent social framework.(
B) The dimensions of great power versus small power: It expresses the extent to which members of society accept inequality in the distribution of power in institutions and organizations, and it affects the way institutions are formed in countries.

C) Avoiding strong uncertainty versus weak avoidance of uncertainty: Avoiding uncertainty expresses the degree to which individuals feel discomfort with ambiguity and uncertainty, and this dimension relates to how society deals with the fact that the future is unknown and whether society is trying to control The future or leave it to happen in any way, as well as this dimension affects the way institutions are formed.

D) Material values versus intangible values: Material values are represented in society's preference for evaluating individuals on the basis of heroism, persistence and material success, and on the contrary, intangible values represent society's preference for moderation, concern for the weak, helping others, and placing relationships on a higher level of considerations. Materialism.

8- Bodies and organizations aiming to standardize and harmonize accounting practices (Ghattas, 2007: 17): Several international bodies have emerged that sought to harmonize accounting practices, and among the most important of these bodies are: the International Accounting Standards Committee (IASC) and the European Market Authority (EEC).

Gray (1988) proposes four hypotheses to link his accounting values with Hofstede's cultural. These hypotheses can be stated as follows: - (2006 Doost 12(:

-Countries with high levels of uncertainty avoidance but low levels of individualism and masculinity are likely to rank high in terms of conservatism.

-Countries with high levels of avoidance of uncertainty and authority but low levels of individualism and masculinity are likely to rank high in terms of secrecy.

Countries with high levels of individualism but low levels of uncertainty avoidance and power dimensions are likely to rank highly in terms of professionalism. 
- Countries with high levels of uncertainty avoidance and distance of power but low levels of individualism are likely to rank high for uniformity.

\section{FOURTH: SOME COUNTRIES' EXPERIENCES IN APPLYING INTERNATIONAL STANDARDS:}

In order to seek to demonstrate the effect of international accounting standards on accounting values through the experiences of a group of countries that have applied these standards, we must first indicate what accounting values correspond to international standards and then indicate the accounting values of the countries that apply those standards, and the researcher has chosen a group of countries Which is characterized by accounting values that are far from the accounting values of the Anglo-Saxon countries due to the proximity of the last countries to the accounting values preferred by international standards in order to know the extent of the impact on those values, which are similar to the accounting values in Iraq and are characterized by uniformity, confidentiality, reservation and legal authority and the table below shows that :

Table (1) the accounting values preferred by international standards

\begin{tabular}{|l|l|}
\hline $\begin{array}{l}\text { Accounting values preferred by } \\
\text { international standards }\end{array}$ & Assumptions / Values Accounting Gray \\
\hline Professional & IProfessionalism versus legal oversight \\
\hline Flexibility & Standardization versus flexibility \\
\hline optimism & Conservation versus optimism \\
\hline Transparency & Confidentiality versus transparency \\
\hline
\end{tabular}

\section{Source: Prepared by the researcher}

\section{1- Egypt:}

Through a survey of a group of Egyptian companies and after the application of international standards for a study prepared, which was largely driven by empirical investigation and the existence of the accounting values of Gray in the Egyptian context, for the following three reasons. First, Egypt has grown rapidly as an emerging market since the early 1990s with many potential opportunities for foreign investment, international joint ventures and. Secondly, the business environment in Egypt has witnessed a major shift towards capitalism over the past few decades, and thus, it may be expected that historically assuming accounting values in Egypt in terms of conservatism, secrecy and legal control, will turn in a new direction: towards optimism, transparency and professionalism, especially after the adoption The latest versions of Egyptian Accounting Standards (EASs). These versions are mostly extracted from International Accounting
Standards (IASs), which are based on Anglo-Saxon assumptions 1. Third, Egypt is an influential country in the Middle East and the results of any inquiry may circulate it to the Arab countries, at least. And Ahmed (2015: 98) confirms in the research paper and through the empirical investigation that there is a tendency for the accounting values of Egyptian companies to agree in line with the Anglo-Saxon. In light of the above, and since the disclosure requirements have changed in the country in recent years due to the issuance of the new version of EASs in 2006, interest has begun to reconsider the existence of the accounting value of confidentiality, reservation, and legal control through an experimental survey on a group of Egyptian companies and by using More recent and comprehensive data showing that the level of discretion and confidentiality has changed over time and that companies now have a tendency to be more transparent and optimistic as a result of applying international standards. 


\section{2-Indonesia:}

In 2011, Indonesia adopted $95 \%$ of international financial reporting standards and work is on schedule and close to complete by 2012. However, IFRSs are not yet allowed for use by domestic companies listed on the stock exchange in 2012. Initially, from The Indonesian Reporting Standards Board is expected to be in compliance with IFRS by 2008. However, by 2010, the IFRS has made significant progress. The delay was mostly due to the need to translate IFRS into Indonesian. The new plan was to be completely close to the International Financial Reporting Standards by 2012. The accounting values in this country are uniform, confidentiality, reservation and legal control, but after applying international standards, it was found that there is a noticeable change in the values of confidentiality and reservation The tendency is more towards optimism and transparency, due to the trend towards the global market and the entry of multinational companies (David, 2013: 634.

\section{3-Saudi Arabia}

The Kingdom of Saudi Arabia, as a member of the Group of Twenty, has embarked on the transformation project and has developed a timetable for adopting IFRS standards on the financial statements of companies listed on the financial market prepared for financial periods as of 1/1/2017. As for other entities, the standards will be applied to the financial statements prepared for the financial periods starting from $1 / 1 / 2018$.

IFRS standards are distinguished by the principle of relying on the principle, and by this they give a space for the financial manager or executive to use his expertise and capabilities in handling and measuring complex or unusual financial operations, and his decision is considered considered if it does not violate the principles and conceptual frameworks stipulated in the standard, with the need to support this with sufficient evidence. The adoption of IFRS on principles reduces the need to enact an accounting rule for each emergency economic situation or transaction, and David, 2013: 677, () explained that achieving long-term stability and IFRS in the Kingdom of Saudi Arabia is critical to achieving its growth. A profound impact on accounting systems and values The IFRS will increase professionalism, optimism, and transparency at the corporate and governmental level. Which will have a positive impact on the general level of professional education of accountants and accounting standards setting bodies and improving their policies and decision-making. The involvement of individual citizens will encourage participating as investors in the local capital markets, which will have a positive impact on public education and contribute to the demographic of the community.

Based on the above and from the experience of countries that have applied international financial reporting standards and from previous studies in this regard, the researcher believes that there is a clear tendency on the accounting values of the countries that have applied these standards for the accounting values that adopt international standards, and therefore the application of international standards has a clear effect on the accounting values.

\section{FIFTH: THE REALITY OF ACCOUNTING VALUES IN IRAQ}

We will try to link the gray accounting values that were mentioned previously with accounting countries with different cultures, and explain the reality of accounting values in Iraq. (Salman et al. 2012: 43(

The first dimension related to professionalism versus legislative control, we find that the countries that consider the role of accounting skills are mainly concerned with the application of detailed legal requirements, as that skill is subject to general regulation or legislative oversight. Among these countries are France and Germany. From social values. But we find otherwise in the Anglo-American countries, where we find professional accounting societies with a long history in which the concept of truth and justice presentation of the financial situation of companies emerges based on accountants' judgments based on their independent skills, and this is identical to the goal related to increasing accounting disclosure. As for the extent to which professionalism can be linked to social values related to individualism, the extent to which professionalism may be linked more tightly to the dimensions of gray authority, avoiding uncertainty between individualism and avoiding uncertainty. The preference for independent professional judgment is in harmony with the preference for a free social framework. Which focuses more on independence, belief in individual decisions and respect for private endeavor. This is also consistent with the weakness of avoiding uncertainty in implementation through the reliance on fair representation and with few rules whenever possible and the 
diversity of professional judgments representing to be more easy and possible. People of different levels of power feel less threatened and more prepared. We note that the culture of the Anglo-American countries (Sweeney, 2002: 76): confidence in anyone towards the other, American identical with professionalism and its relationship to individual dimensions, the extent of power, avoiding the above uncertainty, unlike what is in culture Iraqi.

)Macro) As for the unification with flexibility, it differs in different cultures of the countries. Countries with a macroeconomic suitability to achieve the goals of those countries are a unified (consistent) accounting system, as in the case of imposing tax rules to lure measurement so that they focus on facilitating national planning for the economy. It can be said that Iraq tends to the dimension of consolidation, which has proven (Micro) as an accounting value consistent with its culture, unlike the Anglo-American countries with microeconomics that they are more concerned with the mutual temporal harmony and some degrees of comparison between companies, which leads to flexibility in their accounting applications (13). 2004 (Doupnik

Monotheism has a strong link with the cultural dimension of the avoidance of uncertainty leading to an emphasis on law and shocking orders to behavior as well as the need for written rules and respect for compliance. Likewise, consistency is consistent with the preference of the group over individualism through respect for the collegial models, and the same thing applies to this dimension on its relationship to the extent of power more than the weakness of the authority and all of that authority, all of which depends on it being in harmony with the Iraqi environment.

As for the conservatism versus optimism, it was shown that is controversial and represents a more ancient and possibly more permeable principle of accounting evaluation. On a large scale, conservatism is a fundamental pillar of accountants, whether in their applications through asset measurement or when determining earnings (Bloom, 2009: 109). The reservation imposes itself strongly in the accounting applications of a less powerful number in other countries, such as the United States of America. As for the relationship of reservation with the dimension of avoiding uncertainty, we see it as a close relationship through the reservation of measurement of profits and harmonious assets with a strong avoidance of uncertainty. This results in preventive measures and awareness required for caution. For every future event there is uncertainty, and this is what Iraq tends to.

As for confidentiality versus transparency, we note that confidentiality is closely aligned with reservation, as both include a cautious approach to financial reporting in general, as the scope of confidentiality appears in different countries with a lower level of disclosure, including examples related to secret reserves, and this is what appears in countries such as France, Japan and Germany. . Confidentiality is also consistent with the dimension of social values related to a strong avoidance of uncertainty, because the latter entails the need to restrict the disclosure of information to external parties in order to avoid conflicts and competition and to formulate security. For security. There is also harmony between secrecy and collectivism, unlike individualism, and this can also apply to Iraqi culture

\section{SIXTH: CONCLUSIONS}

The process of developing and developing accounting standards is a continuous process through which accounting responds to what arise from new problems and transactions and to changes that occur in any of the prevailing environmental and societal conditions. International accounting standards have become a reference to which accountants and professionals from most countries of the world return to Especially in developing countries, due to the lack of local standards governing professional practices, and that the difference in accounting values is the result of different cultural, legal, political, social and economic influences of countries. And that the application of international accounting standards does not affect only the accounting practices, but also affects the accounting values of those countries in a different way. As the international accounting standards can clearly affect the accounting values of those countries if the application is complete and in the long term. So we find it necessary to follow an appropriate strategy When issuing accounting standards in each country, which is based on the combination of the positive strategy for building standards and the strategy of importing them. 


\section{SOURCES:}

1-Salman, Amer Muhammad, Muhammad, Safaa Muhammad, Nuri, Amal(2012) (The Role of Culture in Developing Accounting Applications) Journal of Administration and Economics The 35th year - Number Ninety-three

2-Al-Buhais, Essam Mohamed.(2006) "Measuring Diversity in International Accounting Systems", a research published in the Journal of the Islamic University, Volume Four - First Issue - 2006

3-Ghattas, Prince Michael(2007). "The role of environmental variables in developing the accounting dimensions affecting attracting foreign investment." Research presented to the International Trends and Economic Conference, December 2007

.4-Issa, Sirwan Karim.(2004) "Features of the Conceptual Framework for Accountancy in the Iraqi Environment" PhD thesis submitted to the Board of the College of Administration and Economics - Al-Mustansiriya University,

5-Ahmed Bassiouni Shehata, Abdel Wahab Nasr Ali,(2008) "Advanced Financial Accounting: According to the Latest International, American and Arab Accounting Standards", Publisher: Accounting Department, Faculty of Commerce, Alexandria: Egypt, 2008, p .: 36 .

6- Daou Abdel-Qader, Accounting Treatment for Exchange Rate Fluctuations According to International Accounting Standards, Master Thesis, Faculty of Economic Sciences, in-depth Accounting and Tax Studies, Qasidi Merbah University, Ouargla, 2013

7-Ismail Ismail,(2017) International Accounting Standard Twenty-first Effects of Changes in Foreign Currency Exchange Rates, Syrian Association of Certified Public Accountants.

8-Hussein Al-Qadi,( 2009) International Accounting Standard 21, Association of Certified Public Accountants, International Accounting Standards Course, 2009

9 -Khaled Jamal Al Ja arat,( 2015) Summary of International Accounting Standards, Muntakah International on the Role of International Accounting Standards in Activating the Performance of Governmental Institutions, Qasidi Marbah University, and Warkna, IAS-IFRS-IPSAS

10-Salah Al-Din Ibrahim Mustafa,(2016) Advanced Accounting, Publications of the Saudi Accounting Association, Fourth Edition,

11-Al-Hinnawi, Muhammad Saleh and Mustafa, Nihal Farid and Al-Abd, Jalal Ibrahim: (2007 )Stock and Bond Valuation (Financial Engineering Entrance), Modern University Office, Alexandria, Egypt,

12- Faris, Othman Abdel Salam: Analysis of the mutual impact of interest rate change on the movement of exchange rates, research presented for a master's degree in economics of international relations, supervised by Dr. Jawad M.

13-Al-Rawi, Khaled Wahib: , (2005) Financial Risk Management, Dar Al-Masirah for Publishing and Distribution, Amman, Jordan, 2009, Dean Ali, Faculty of Economics, Damascus University, Damascus, Syria, 2011

14 -Al-Tarrad, Ismail Ibrahim(2016) Foreign Exchange Administration, Dar Wael for Printing and Publishing, 2nd floor, Amman, Jordan, p.20

15- Cowell, Brian: (2005), Foreign Exchange Markets, Dar Al-Farouq Publishing and Distribution,

16-Ahmed Abousamak(2015) (Is there a shift in the accounting values in Egypt towards optimism transparency and professionalism), Afro-Asian J. Finance and Accounting, Vol. 5, No. 3, 
17-David R. Borker,(2013)(Accounting And Cultural Values: IFRS In 3G Economies) International Business \& Economics Research Journal - June 2013, Volume 12, Number 6

18-Frederick D. S. Choi; K. Meek Gray,(2008) "International Accounting", Person Education International, (6): 2008, P: 36.

19-Bloom,R.,M.A. Naciri,2009) "Accounting Standards Setting and Culture: A Comparative Analysis of The United States, Canada, England, West Germany, Australia, New Zealand, Sweden, Japan, Ad Switzerland", The International Journal of Accounting, vol.24, (1),

20 -Doost,R.K.,K.M. Ligon, (2006)"HowU.S. And European Accounting Practices Differ", Management Accounting (U.S.A), .

21 -Mc Sweeney,(2012) "Hofsted's Model of National Cultural Differences and Their Consequences", Human Relations,

22- Doupnik,T.S., and G.T. Tsakumin,( 2004), "A Critical Review of Gray's Theory of Cultural Relevance and Suggestions For Future Research", Journal of Accounting Literature (23):

23- Bob Parker, "Accountants Galore", Accountancy (November 2001.

24-Dicks . James:((2016) Forex Trading Secrets, Mc Graw- Hill companies, New York, USA,.

25-Cheng .Grace(2017) 7Winning Strategies for Trading Forex, Harriman House Ltd, London, UK,.

26-F.Martines. Jared: (2007). 10 Essentials of Forex Trading, Mc Graw- Hill companies, New York, USA

27-R.Krugman. Paul(2005): International Economics Theory and Policy, seventh edition ,

28-Galant. Mark \& Dolan Brian(2007): Currency Trading for Dummies, Wiley Publishing Inc, New jersey, USA,.

29-Jagerson. John \& Hansen. Wade(2006): Profiting with Forex, Mc Graw- Hill companies, New York, USA,.

29-Ed. Ponsi: ,(2007) Forex Patterns and Probabilities, John Wiley \& Sons Inc, New jersey, USA 